Am J Obstet Gynecol. 2016 September ; 215(3): 314.e1-314.e5. doi:10.1016/j.ajog.2016.01.170.

\title{
The Effect of Antidepressants on Fertility
}

\author{
Ms. Marianne M. CASILLA-LENNON, BS, Dr. Samantha MELTZER-BRODY, MD, and Dr. Anne \\ Z. STEINER, MD, MPH \\ Department of Obstetrics and Gynecology, University of North Carolina School of Medicine, \\ Chapel Hill, NC (Ms. Lennon and Dr. Steiner); Department of Psychiatry, University of North \\ Carolina, Chapel Hill, NC (Dr. Meltzer-Brody)
}

\section{Abstract}

BACKGROUND-Information on the effects of different pharmaceuticals on fertility is sparse. Human and animal models indicate that antidepressant use could have a negative effect on fertility through alteration of levels of the neurosteroid, allopregnanolone.

OBJECTIVE-The objective of this study is to assess the effects of antidepressants on the natural fertility in women.

STUDY DESIGN-A secondary analysis of data from Time to Conceive, a prospective cohort study, was conducted. Women aged 30-44 without history of infertility, early in their attempts to conceive, were followed with standardized pregnancy testing until pregnancy was detected. Medication use was assessed at enrollment, daily for up to four months, and then monthly. For this analysis, discrete time regression models were created to calculate the association between antidepressant use and fecundability. Potential confounders: age, body mass index, caffeine, alcohol use, and education were included in all models.

RESULTS-Ninety-two (9.6\%) of 957 women reported antidepressant use while attempting to conceive. Women taking antidepressants were more likely to be non-Hispanic Caucasian (91\% vs. $75 \%, \mathrm{p}<0.01)$ and to consume alcoholic beverages ( $74 \%$ vs. $61 \%, \mathrm{p}<0.01)$. Antidepressant use at enrollment had an adjusted FR of 0.86 (95\% CI: 0.63-1.20). However, time varying analyses suggested that antidepressant use in a given cycle is associated with a reduced probability of conceiving in that cycle (adjusted FR 0.75 95\% CI: 0.53-1.06). After adjusting for history of depression or restricting the analysis to women who reported a history of depression, the association between antidepressant use and decreased fecundability remained [adjusted FR 0.66 (95\% CI 0.45-0.97) and (adjusted FR 0.64, 95\% CI: 0.43-0.94), respectively].

Corresponding Author: Anne Z. Steiner, MD, MPH, University of North Carolina, CB\#7570, 4001 Old Clinic Building, Chapel Hill, NC 27599, Tele: (919) 966-5283, Fax: (919) 966-5214, asteiner@med.unc.edu.

Conflicts of Interest: The authors report no conflicts of interest.

Presentation: This abstract was presented at the $63^{\text {rd }}$ Annual Meeting of the Pacific Coast Reproductive Society; Palm Springs, CA, March, 2015.

Condensation: Antidepressants, but not depression, may negatively affect natural fertility.

Publisher's Disclaimer: This is a PDF file of an unedited manuscript that has been accepted for publication. As a service to our customers we are providing this early version of the manuscript. The manuscript will undergo copyediting, typesetting, and review of the resulting proof before it is published in its final citable form. Please note that during the production process errors may be discovered which could affect the content, and all legal disclaimers that apply to the journal pertain. 
CONCLUSION-Our data suggest that antidepressants may reduce the probability of a woman with a history of depression to conceive naturally. Future studies are needed to differentiate the extent to which this association is due to the antidepressant itself versus the underlying depression.

\section{Keywords}

Antidepressants; depression; fertility; fecundability

\section{INTRODUCTION}

Antidepressants are the first line of treatment for unipolar major depression ${ }^{1}$ and a number of other mood disorders, like obsessive compulsive disorder. ${ }^{2}$ In 2011, antidepressants were the most dispensed drug in the United States accounting for over 260 million prescriptions. ${ }^{3}$ Antidepressants were disproportionately used by women, ${ }^{4}$ the majority of reproductive age, compared to men. ${ }^{5}$ Although there has been significant research on the teratogenicity of antidepressants, little is known about their direct impact on fertility.

The three most commonly prescribed classes of antidepressants increase allopregnanolone, ${ }^{6}$ a progesterone derivative considered a neurosteroid that is produced and is neuroactive in the brain. Allopregnanolone is a positive allosteric modulator of the gamma aminobutyric acid $\left(\mathrm{GABA}_{\mathrm{A}}\right)$ receptor. Its presence enhances the activity of GABA, which is the main inhibitory neurotransmitter in the central nervous system, including the hypothalamus.

Research on rodents suggest that an antidepressant-induced increase in allopregnanolone levels could lead to dysregulation of the hypothalamic-pituitary-ovarian (HPO) axis. Incubation of hypothalamic tissue with allopregnanolone suppresses GnRH release in a concentration-dependent manner. The effects are blocked with the addition of a GABAantagonist, suggesting that allopregnanolone increases GABA activity, suppressing GnRH release. ${ }^{7}$ Accordingly, injection of allopregnanolone into the hypothalamus of rats has been shown to decrease circulating LH levels and result in fewer oocytes at oestrus. ${ }^{6}$ The results of animal models have been consistent in humans. Intravenous administration of allopregnanolone in healthy, fertile women decreases follicle stimulating hormone (FSH) and LH levels ${ }^{8}$ and subsequently decreases rates of ovulation. This dysregulation in allopregnanolone could inhibit the pulsatile action of GnRH needed to sustain proper synchronization of ovulation, resulting in infertility.

The above evidence suggests that antidepressants may contribute to changes in the HPO axis through their GABAergic action. HPO axis dysfunction can manifest in numerous ways, including anovulation or luteal phase defects, which can negatively impact a woman's ability to conceive. We hypothesized that antidepressant use would impair natural fertility, which we examined by analyzing the effect of antidepressants on fecundability, the probability of conceiving in a menstrual cycle.

\section{MATERIALS AND METHODS}

This study is a secondary analysis of Time to Conceive (TTC), an ongoing prospective timeto-pregnancy cohort study approved by the institutional review board at the University of 
North Carolina. A detailed description of the TTC study has been published previously. ${ }^{9}$ In brief, women were recruited to the study via community-based fliers, informational emails, internet, radio, television and print advertising, and community blogs. English-speaking women 30 to 44 years old, who had been attempting to conceive for less than three months, were eligible to participate. Women with a history of infertility, polycystic ovary syndrome, pelvic inflammatory disease, endometriosis, pelvic radiation, or a partner with a history of infertility were excluded. Our analysis includes women enrolled between April 2008 and July 2015. Information was collected via a web-based questionnaires and daily diaries. At enrollment women provided demographic information, medical and surgical history, obstetric, gynecologic, and menstrual history, information on behaviors, height and weight, and pregnancy history, as well as partner demographics. Women were asked if they had a history of anxiety or depression (yes/no). The question was not restricted to any specific type of depression or anxiety. The Cerner Multum drug database system was embedded to identify and record over-the-counter and prescription medication use. This comprehensive database included dosing information and drug names, both generic and brand names.

While attempting to conceive, women completed an online daily diary for four months or until pregnancy was detected. The daily diary collected information on vaginal bleeding, intercourse, pregnancy test results, and medication use. If the woman did not conceive in the first four months of enrollment, she completed an online questionnaire monthly thereafter, which also collected information on medication use. The women were followed for twelve months or until pregnancy was achieved. Pregnancy tests (sensitivity $=20 \mathrm{mIU} \mathrm{hCG} / \mathrm{mL}$ ) were provided with standardized instructions. For this analysis, a positive pregnancy test was our primary outcome of interest.

Antidepressants were categorized by class via mechanism of action. A comprehensive list of traditional antidepressants was constructed. Our list included selective serotonin reuptake inhibitors (SSRIs), serotonin/norepinephrine reuptake inhibitors, serotonin antagonist and reuptake inhibitors, norepinephrine reuptake inhibitors, norepinephrine/dopamine reuptake inhibitors, tri and tetracyclic antidepressants (TCAs), monoamine oxidase inhibitors, and other antidepressants. Adjunct antidepressants and other psychotropic medications with antidepressant action were excluded.

\section{Statistical Analysis}

Women were categorized by antidepressant use (yes/no). Antidepressant use was categorized by 1) use at enrollment, 2) use at any given time during the study, and 3) use in a given menstrual cycle. Bivariate analyses, using chi-square tests, were used to compare demographics and potential covariates (age, race, education level, pregnancy history, menstrual cycle regularity and length, previous contraceptive use, body mass index [BMI], partner age, smoking status, alcohol use, and caffeine use) between the antidepressant users (at any given time in the study) and non-users.

Discrete-time survival models were constructed to assess the relationship between 1) antidepressant use at enrollment and fecundability and, as antidepressant use of an individual woman could vary over time, 2) antidepressant use in a given cycle and fecundability in that given cycle. All analyses were restricted to the first nine cycles of 
attempt, due to few women remaining after that time. All models accounted for both the right censoring and left truncation (due to women enrolling in cycles 1,2,3, or 4 of their pregnancy attempt) present in the data. In these models, a fecundability ratio (FR) less than 1.0 suggested reduced fecundability.

In all adjusted models we included both the covariates strongly associated with fecundability or antidepressants and those identified in multiple prior studies as related to fecundability. These covariates were age, Caucasian race (yes/no), body mass index, education level, and alcohol use (yes/no). Maternal age was collapsed into three categories (30-34, 35-37, and $38-44$ years of age), and BMI was categorized into four groups ( $₫ 8.4,18.5-24.9,25.0$ 29.9 , and $\geq 30 \mathrm{~kg} / \mathrm{m}^{2}$ ). Additional analyses adjusted for history of anxiety/depression as reported in the baseline questionnaire and restricted analysis to those women, who reported a history of anxiety/depression. In an attempt to explore the extent to which underlying anxiety/depression may play a role in the relationship between antidepressants and fertility, we analyzed the relationship between history of anxiety/depression, as reported in the baseline questionnaire and fecundability.

\section{RESULTS}

A total of 957 women and 3,355 menstrual cycles were included in this analysis. Of the analysis cohort, $70 \%$ of women were $30-34$ years old, $18 \%$ were $35-37$ years old, and $12 \%$ were 38-44 years old. Participants tended to be Caucasian (76\%), highly educated (72\% with some graduate education or more), and normal weight (62\%). Six hundred twenty-two $(65 \%)$ of subjects conceived during their first nine cycles of attempt. Analysis was restricted to the first nine cycles due to high levels of drop-out past this point.

Ninety-two (9.6\%) women reported antidepressant use at some point during enrollment. Antidepressant use was reported by $7.6 \%$ of women in the first cycle of attempt, $9.0 \%$ in the second, $8.9 \%$ in the third, $8.2 \%$ in the sixth, and $11.0 \%$ in the eighth. The most frequently used antidepressants were SSRIs and all antidepressants, except one report of TCAs, were reuptake inhibitors. Women taking antidepressants were more likely to be non-Hispanic Caucasian ( $91 \%$ vs. $75 \%, p<0.01)$ and to consume alcoholic beverages ( $74 \%$ vs. $61 \%$, $p<0.01)$. There were no differences in other variables analyzed (Table 1). Menstrual cycle length and history of regular menstrual cycles did not differ at baseline by antidepressant use. Antidepressant users at enrollment reported on average 2.18 [standard deviation (SD) 1.25] acts of intercourse per week, which did not differ significantly from non-users at that time with 2.38 (SD 1.59) act per weeks, $p=0.27$. Women reporting a history of depression had similar fecundability to those who did not (adjusted FR 1.03, 95\% CI: 0.82-1.24).

Initial models suggested minimal to no effect of antidepressants on fecundability (Figure 1) when analyzing baseline antidepressant use; women who were taking antidepressants at enrollment had an adjusted FR of 0.86 (95\% CI: 0.63-1.20). When analyzing cycles individually, time varying analyses suggested that antidepressant use in a given cycle was associated with a reduced probability of conceiving in that cycle (adjusted FR $0.7595 \%$ CI: 0.53-1.06). After adjusting for a history of anxiety/depression as reported on the baseline questionnaire, the association between antidepressant use and fecundability remained 
[adjusted FR 0.66 (95\% CI 0.45-0.97)]. When the analyses were restricted to women with a history of anxiety/depression, the association also remained (adjusted FR $0.64,95 \% \mathrm{CI}$ : 0.43-0.94).

\section{DISCUSSION}

In this prospective cohort study we found that $9.6 \%$ of women took antidepressants while trying to conceive. Almost all antidepressants used in our study were reuptake inhibitors, sharing a similar mechanism of action. Women in our study who took antidepressants tended to be non-Hispanic Caucasian and more likely to consume alcoholic beverages. History of depression or anxiety was not associated with fecundability. Antidepressant use within a given menstrual cycle was associated with a lower probability of conceiving among women, who reported a history of anxiety or depression.

Antidepressant use in our cohort was similar to that in previous studies. A cross sectional study of 12,637 Americans found antidepressant use in women aged 18-39 to be $9.2 \%{ }^{4}$ Another study found similar rates of antidepressant use in this age group at $9.9 \% .{ }^{10} \mathrm{In}$ addition, a study of antidepressant use during pre-conception and early pregnancy reported a rate of $10.0 \%$ and was similar in regards to age and race. ${ }^{11}$ Retrospective studies relying on reported antidepressant use in IVF recipients reported significantly lower rates than prospective studies. ${ }^{11-14}$

Prior studies reported higher rates of antidepressant use in older women and women of Caucasian race. ${ }^{4,10}$ In our study antidepressant users did not differ from non-users by race or age. The age distribution did not significantly differ by antidepressant use. Regarding race distribution, $79 \%$ of antidepressant users were Non-Hispanic Caucasian, while $76 \%$ of nonusers were non-Hispanic Caucasian. Our inability to detect previously observed associations may be due to the relatively narrow age range and underrepresentation of minorities in this study.

We did not find any differences in the reported regularity or length of menstrual cycles between women using and not using antidepressants. If menstrual cycle characteristics had been different between groups, this may have suggested HPO axis dysfunction. However, menstrual cycles tend to be highly variable ${ }^{15}$ and a lack of these findings does not exclude the possibility of HPO axis dysregulation leading to anovulation or luteal phase defects.

Our study found lower fecundability in cycles in which a woman took an antidepressant. This finding was statistically significant after adjusting for history of anxiety or depression or restricting the analysis to those that reported a history of anxiety or depression. To our knowledge, this is the first prospective study to look at the effect of antidepressants on fertility. In a case control study, Grodstein et al. found that women who took antidepressants for more than six months had 2.9 times the odds of infertility (95\% CI 0.9-8.3). This finding was based on five cases who took antidepressants. ${ }^{19}$ Klock et al. performed a retrospective study to analyze the effect of SSRIs on the success of IVF treatments, reporting that the group of women using SSRIs had a lower pregnancy rate than non-users (40\% vs. 51\%). Their findings were limited by a small sample size and were not statistically significant. ${ }^{12}$ 
The observed association between antidepressants and fecundability could be due to the antidepressants itself or the underlying fertility. This study was not designed to look at the relationship between depression and fecundability. There was a single question on the enrollment questionnaire that queried about history of underlying depression or anxiety. This simple measure was not associated with fecundability. However, we are unable to determine the extent to which antidepressants users or non-users suffered from depression or residual depressive symptoms. Therefore, this study is unable to truly differentiate the effect of the underlying depression from the antidepressant. Future studies could use validated questionnaires to assess anxiety and depression symptoms.

The true relationship between depression and fertility is unknown. Odegard found in a study of 30,438 married or previously married women in Norway hospitalized for psychiatric disorders, that women with affective psychoses had a similar number of observed children as expected for the general population. ${ }^{16}$ This study assessed severe psychiatric conditions and didn't specifically stratify the differences in mood disorders alone. Harlow et al found, in a prospective cohort of women going through menopause, that women with a history of depression reported fewer live births. ${ }^{17}$ Neither of these studies account for desires to conceive. In a prospective time-to-pregnancy study, Lynch et al. used the Hospital Anxiety and Depression Scale to assess the association between depression and fecundability. They did not find an association between depression scores and fecundability. However, depression scores for their cohort were within the normal range; thus they were not able to assess the impact of depressive disorders. ${ }^{18}$

Confounding by indication, in which a disease is associated with the use of a medication and the outcome, is a problem in may many pharmacological studies. ${ }^{20} \mathrm{~A}$ recent study by Andersen et al. examined the relationship between antidepressant use and miscarriage using a pharmacy database. ${ }^{21}$ The authors found an increased risk of miscarriage in those women taking antidepressants during the first trimester (1.27 HR; 95\% CI 1.22-1.33) compared to women that did not. However, they found a similarly increased risk of miscarriage in those women that stopped the antidepressant prior to conceiving (1.24 HR, 95\% CI 1.18-1.30). ${ }^{21}$ This would suggest a potential for confounding by indication with this class of medication. To try to account for the possibility of confounding by indication, we restricted our analysis to women who reported a history of anxiety/depression. However, we did not account for current disease or severity of disease. Future studies may need to collect more information to allow the use of propensity scores (to predict probability of using antidepressants) in analyses.

Our study is not without limitations. By design it includes older reproductive-aged women. While this increases the prevalence of antidepressant use, it may decrease generalizability. Although we identified numerous variables known to affect both depression and fertility, the nature of an observational study precludes us from adjusting for all possible confounders. The outcome we used was an epidemiological measure of fecundability, not incidence of infertility, and the outcome was pregnancy, not live birth. One would presume, however, that decreased fecundability would result in increased rates of infertility. Because our study was not originally designed to assess depression, we relied on a self-report of a history of 
depression/anxiety. As discussed above, this study cannot differentiate between active or past depression nor between anxiety and depression.

Our study design was the most important strength of our study. A prospective cohort provides the strongest evidence when assessing pharmaceuticals on women attempting to conceive, as randomized controlled trials are not done in this context. ${ }^{20}$ Cross-sectional studies are limited by their inability to determine temporal causality. The online selfreported daily diaries allowed for accuracy, as well as privacy, compared to face-to-face interviews, which may be especially important when assessing sensitive information. ${ }^{22}$ To further improve accuracy by avoiding misclassification and monitoring adherence of antidepressants, the Center Multum drug database was used.

In conclusion, antidepressants are among the most widely used medications in reproductiveaged women in the United States. Our study suggests that antidepressant use in women with a history of anxiety or depression diminishes natural fertility. While this is concerning, it is possible that the indication for the antidepressant is the causal factor. Thus, this study alone cannot be used as justification for women to stop their antidepressants when attempting to conceive.

\section{Acknowledgments}

Funding: This work was funded by grants T35-DK007386 and R01067683 from the NIH/NICHD.

\section{References}

1. Davidson JRT. Major depressive disorder treatment guidelines in America and Europe. J Clin Psychiatry. 2010; 71(Suppl E1):e04.doi: 10.4088/JCP.9058se1c.04gry [PubMed: 20371031]

2. Kellner M. Drug treatment of obsessive-compulsive disorder. Dialogues Clin Neurosci. 2010; 12(2): 187-197. [PubMed: 20623923]

3. Lindsley CW. The Top Prescription Drugs of 2011 in the United States: Antipsychotics and Antidepressants Once Again Lead CNS Therapeutics. ACS Chem Neurosci. 2012; 3(8):630-631. DOI: 10.1021/cn3000923 [PubMed: 22896807]

4. Pratt, L.; Brody, D.; Gu, Q. Antidepressant use in persons aged 12 and over: United States, 20052008. National Center for Health Statistics; Hyattsville, MD: 2011. NCHS data brief, no 76[Internet]Available from: http://www.cdc.gov/nchs/data/databriefs/db76.htm [cited 2014 Jul 15]

5. Farr SL, Bitsko RH, Hayes DK, Dietz PM. Mental health and access to services among US women of reproductive age. Am J Obstet Gynecol. 2010; 203(6):542.e1-e9. DOI: 10.1016/j.ajog. 2010.07.007 [PubMed: 20817143]

6. Uzunova V, Wrynn AS, Kinnunen A, Ceci M, Kohler C, Uzunov DP. Chronic antidepressants reverse cerebrocortical allopregnanolone decline in the olfactory bulbectomized rat. Eur J Pharmacol. 2004; 486(1):31-34. [PubMed: 14751405]

7. Calogero AE, Palumbo MA, Bosboom AM, et al. The neuroactive steroid allopregnanolone suppresses hypothalamic gonadotropin-releasing hormone release through a mechanism mediated by the gamma-aminobutyric acidA receptor. J Endocrinol. 1998; 158(1):121-125. [PubMed: 9713333]

8. Timby E, Hedström H, Bäckström T, Sundström-Poromaa I, Nyberg S, Bixo M. Allopregnanolone, a GABAA receptor agonist, decreases gonadotropin levels in women. A preliminary study. Gynecol Endocrinol Off J Int Soc Gynecol Endocrinol. 2011; 27(12):1087-1093. DOI: $10.3109 / 09513590.2010 .540603$ 
9. Steiner AZ, Herring AH, Kesner JS, et al. Antimüllerian hormone as a predictor of natural fecundability in women aged 30-42 years. Obstet Gynecol. 2011; 117(4):798-804. DOI: 10.1097/ AOG.0b013e3182116bc8 [PubMed: 21422850]

10. Olfson M, Marcus SC. National patterns in antidepressant medication treatment. Arch Gen Psychiatry. 2009; 66(8):848-856. DOI: 10.1001/archgenpsychiatry.2009.81 [PubMed: 19652124]

11. Cooper WO, Willy ME, Pont SJ, Ray WA. Increasing use of antidepressants in pregnancy. Am J Obstet Gynecol. 2007; 196(6):544.e1-e544.e5. DOI: 10.1016/j.ajog.2007.01.033 [PubMed: 17547888]

12. Klock SC, Sheinin S, Kazer R, Zhang X. A pilot study of the relationship between selective serotonin reuptake inhibitors and in vitro fertilization outcome. Fertil Steril. 2004; 82(4):968-969. DOI: 10.1016/j.fertnstert.2004.02.139 [PubMed: 15482784]

13. Friedman BE, Rogers JL, Shahine LK, Westphal LM, Lathi RB. Effect of selective serotonin reuptake inhibitors on in vitro fertilization outcome. Fertil Steril. 2009; 92(4):1312-1314. DOI: 10.1016/j.fertnstert.2009.03.060 [PubMed: 19423105]

14. Van Gelder MMHJ, van Rooij IALM, de Walle HEK, Roeleveld N, Bakker MK. Maternal Recall of Prescription Medication Use During Pregnancy Using a Paper-Based Questionnaire: A Validation Study in The Netherlands. Drug Saf. 2013; 36(1):43-54. DOI: 10.1007/ s40264-012-0004-8 [PubMed: 23315295]

15. Münster K, Schmidt L, Helm P. Length and variation in the menstrual cycle--a cross-sectional study from a Danish county. Br J Obstet Gynaecol. 1992; 99(5):422-429. [PubMed: 1622917]

16. Odegård O. Fertility of psychiatric first admissions in Norway 1936-1975. Acta Psychiatr Scand. 1980; 62(3):212-220. [PubMed: 7457168]

17. Harlow BL, Wise LA, Otto MW, Soares CN, Cohen LS. Depression and its influence on reproductive endocrine and menstrual cycle markers associated with perimenopause: the Harvard Study of Moods and Cycles. Arch Gen Psychiatry. 2003; 60(1):29-36. [PubMed: 12511170]

18. Lynch CD, Sundaram R, Buck Louis GM, Lum KJ, Pyper C. Are increased levels of self-reported psychosocial stress, anxiety, and depression associated with fecundity? Fertil Steril. 2012; 98(2): 453-458. DOI: 10.1016/j.fertnstert.2012.05.018 [PubMed: 22698634]

19. Grodstein F, Goldman MB, Ryan L, Cramer DW. Self-reported use of pharmaceuticals and primary ovulatory infertility. Epidemiol Camb Mass. 1993; 4(2):151-156.

20. Koren G, Nickel S. Sources of bias in signals of pharmaceutical safety in pregnancy. Clin Investig Med Online. 2010; 33(6):E349-E355.

21. Andersen JT, Andersen NL, Horwitz H, Poulsen HE, Jimenez-Solem E. Exposure to Selective Serotonin Reuptake Inhibitors in Early Pregnancy and the Risk of Miscarriage. Obstet Gynecol. 2014; 124(4):655-661. DOI: 10.1097/AOG.0000000000000447 [PubMed: 25198261]

22. Perlis TE, Des Jarlais DC, Friedman SR, Arasteh K, Turner CF. Audio-computerized selfinterviewing versus face-to-face interviewing for research data collection at drug abuse treatment programs. Addict Abingdon Engl. 2004; 99(7):885-896. DOI: 10.1111/j.1360-0443.2004.00740.x 


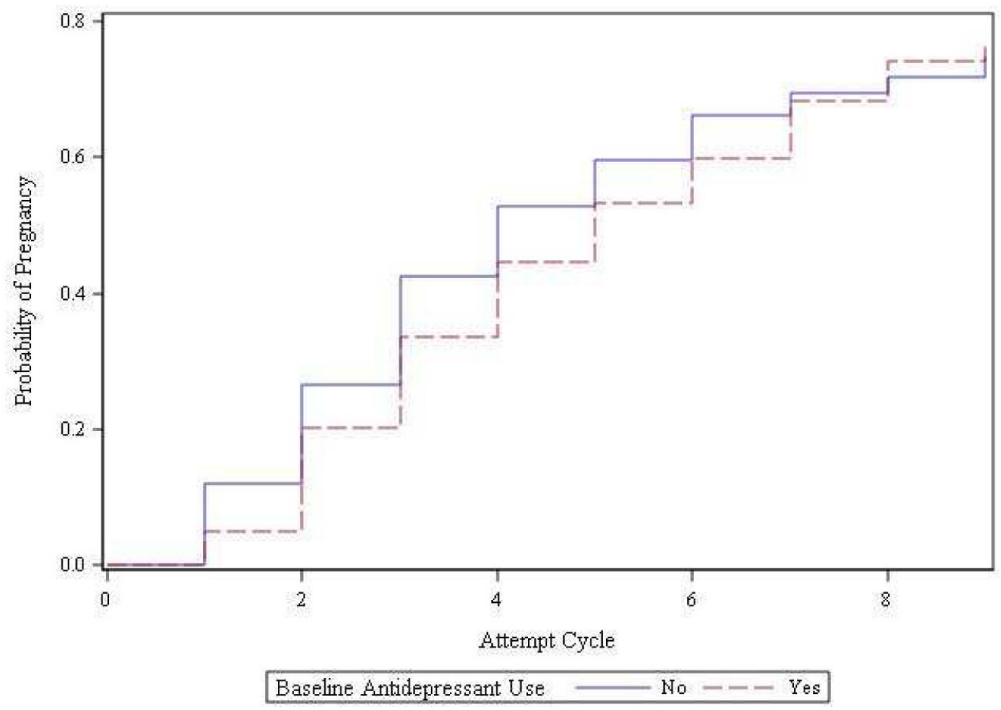

Figure 1.

Unadjusted Kaplan-Meier Curves of time to pregnancy, according to baseline antidepressant use. 
Table 1

Baseline Characteristics of Women taking Antidepressants.

\begin{tabular}{|c|c|c|c|c|}
\hline \multirow{2}{*}{\begin{tabular}{|l} 
\\
Characteristic
\end{tabular}} & \multirow[b]{2}{*}{ Category } & \multicolumn{2}{|c|}{$\begin{array}{l}\text { Antidepressant taken } \\
\text { during study }\end{array}$} & \multirow[b]{2}{*}{$p$} \\
\hline & & $\begin{array}{l}\text { No }(\%) \\
\text { N=865 }\end{array}$ & $\begin{array}{l}\text { Yes }(\%) \\
\mathrm{N}=92\end{array}$ & \\
\hline \multirow[t]{3}{*}{ Age (years) } & $30-34$ & $611(70)$ & $64(69)$ & 0.46 \\
\hline & 35 to 37 & $157(18)$ & $14(15)$ & \\
\hline & 38 and over & $97(11)$ & $14(15)$ & \\
\hline \multirow[t]{2}{*}{ Race } & $\begin{array}{l}\text { Non-Hispanic } \\
\text { Caucasian }\end{array}$ & $652(75)$ & $84(91)$ & $<.01$ \\
\hline & Other & $213(25)$ & $8(8)$ & \\
\hline \multirow[t]{4}{*}{ Education level } & $\begin{array}{l}\text { Less than college } \\
\text { degree }\end{array}$ & $71(8)$ & $5(5)$ & 0.77 \\
\hline & College degree & $174(20)$ & $17(18)$ & \\
\hline & $\begin{array}{l}\text { Some } \\
\text { graduate/masters }\end{array}$ & $79(9)$ & $11(12)$ & \\
\hline & $\begin{array}{l}\text { Completed } \\
\text { postgraduate }\end{array}$ & $541(63)$ & $59(64)$ & \\
\hline \multirow[t]{2}{*}{ Nulligravid } & $\begin{array}{l}\text { Previous } \\
\text { pregnancy }\end{array}$ & $445(51)$ & $53(58)$ & 0.26 \\
\hline & $\begin{array}{l}\text { Never been } \\
\text { pregnant }\end{array}$ & $420(49)$ & $30(42)$ & \\
\hline \multirow[t]{2}{*}{ Regular Menstrual Cycles } & No & $122(14)$ & $13(14)$ & 1.00 \\
\hline & Yes & $742(86)$ & $79(86)$ & \\
\hline \multirow[t]{4}{*}{ Body Mass Index $\left(\mathrm{kg} / \mathrm{m}^{\wedge} 2\right)$} & less than 18.5 & $23(3)$ & $1(1)$ & 0.50 \\
\hline & 18.5 to 24.9 & $538(62)$ & $54(59)$ & \\
\hline & 25 to 29.9 & $175(20)$ & $24(26)$ & \\
\hline & 30 and over & $128(15)$ & $13(14)$ & \\
\hline \multirow[t]{2}{*}{ Current Smoker } & No & $852(99)$ & $91(99)$ & 0.75 \\
\hline & Yes & $13(1)$ & $1(1)$ & \\
\hline \multirow[t]{2}{*}{ Partner age (years) } & $<50$ & $853(99)$ & $92(100)$ & 0.28 \\
\hline & 50 or more & $11(1)$ & $0(0)$ & \\
\hline \multirow[t]{2}{*}{$\begin{array}{l}\text { Past Year Hormonal } \\
\text { contraceptive use }\end{array}$} & No & $474(55)$ & $44(48)$ & 0.20 \\
\hline & Yes & $391(45)$ & $48(52)$ & \\
\hline \multirow{2}{*}{$\begin{array}{l}\text { Caffeinated Beverage } \\
\text { Consumption }\end{array}$} & No & $163(19)$ & $15(16)$ & 0.04 \\
\hline & Yes & $701(81)$ & $77(84)$ & \\
\hline \multirow[t]{2}{*}{ Alcohol Consumption } & No & 335 (39) & $24(26)$ & 0.01 \\
\hline & Yes & $526(61)$ & $67(74)$ & \\
\hline \multirow{3}{*}{$\begin{array}{l}\text { Average Menstrual Cycle } \\
\text { Length }\end{array}$} & 25 or fewer days & $75(9)$ & $12(13)$ & 0.28 \\
\hline & 26-30 days & $618(72)$ & $61(67)$ & \\
\hline & 30-35 days & $126(15)$ & $16(18)$ & \\
\hline
\end{tabular}

Am J Obstet Gynecol. Author manuscript; available in PMC 2017 September 01. 


\begin{tabular}{|l|l|l|l|l|}
\hline \multicolumn{2}{|c|}{} & \multicolumn{2}{|l|}{$\begin{array}{l}\text { Antidepressant taken } \\
\text { during study }\end{array}$} & \\
\hline Characteristic & Category & $\begin{array}{l}\text { No (\%) } \\
\text { N=865 }\end{array}$ & $\begin{array}{l}\text { Yes }(\%) \\
\text { N=92 }\end{array}$ & $p$ \\
\hline & 36 or more days & $42(5)$ & $2(2)$ & \\
\hline
\end{tabular}

